\title{
NEXT GENERATION BUILDING DIAGNOSTICS - CORROSION DETECTION
}

\author{
Ralf W. Arndt ${ }^{1}$ \\ ${ }^{1}$ FH Erfurt, Altonaer Str. 25, 99085 Erfurt, Germany, ralf.arndt@fh-erfurt.de
}

\begin{abstract}
Non-destructive testing (NDT) has become established as an instrument of quality assurance in many areas of industrial materials testing. The cost-intensive NDT methods are worthwhile because they avoid or minimize replacement or expensive repair measures. This development is also recognizable in the building industry.

This contribution presents the latest developments in the field of reinforced concrete diagnostics and discusses their possibilities and limitations and concludes with the latest development of FH Erfurt (FHE) in the field of corrosion diagnostics in reinforced concrete. The new method developed and patented by FHE of active electrochemical, ion mobility and passivation (AECIP) testing uses a semi-destructive active electrochemical approach to characterize the passivated layer of steel reinforcement in interaction with concrete mixtures, aggregates, recipes, post treatment and rehabilitation measures of structures and structural elements made of steel reinforced concrete and is the focus of this paper.
\end{abstract}

Keywords; Non-destructive testing, reinforced concrete, steel reinforcement, aggregates

\section{INTRODUCTION}

In new buildings the reinforcing steel is usually protected against corrosion by the high alkalinity of the pore solution that forms a very thin but practically non-porous passive layer around the reinforcement. By reducing the $\mathrm{pH}$, this passive layer is destroyed and thus the corrosion protection for the reinforcing steel is lost. If oxygen (cracks) and water (pore water) are present steel corrosion can occur.

The main reasons for depassivation of concrete are carbonation of concrete and chloride penetration. Carbonation induced corrosion is a problem when the concrete cover is small or it's a concrete of bad quality with well-connected open pores and a low cement ratio with poor curing. Not only on US highway and civil structures, chloride induced corrosion is the far greater problem (Broomfield 2007, NACE, 2001), that can result in different phases of chloride induced reinforcing steel corrosion in concrete (Melchers/ Li 2006, Weyers et al. 1994, Chen/Mahadevan 2008). Up to nine different phases of chloride induced rebar corrosion damage can thus be distinguished as shown in figure 1 (Arndt/Jalinoos 2009, p. 3-4).

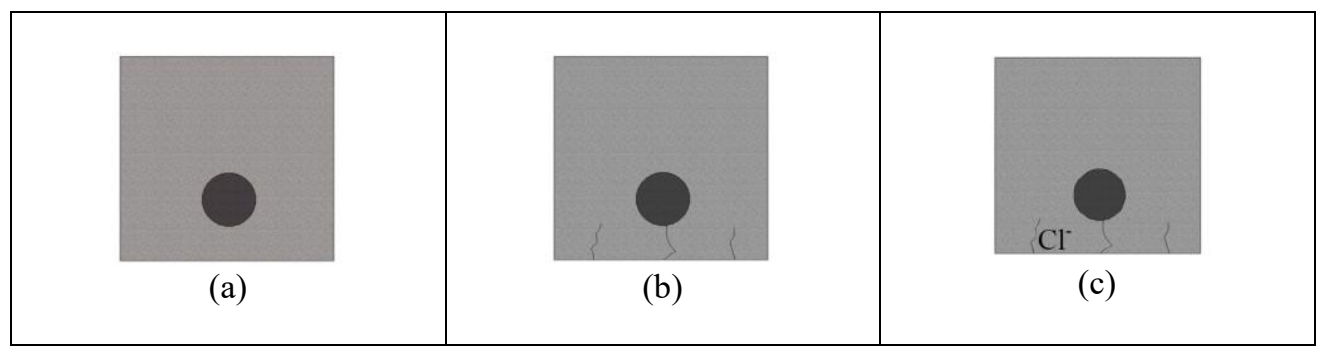




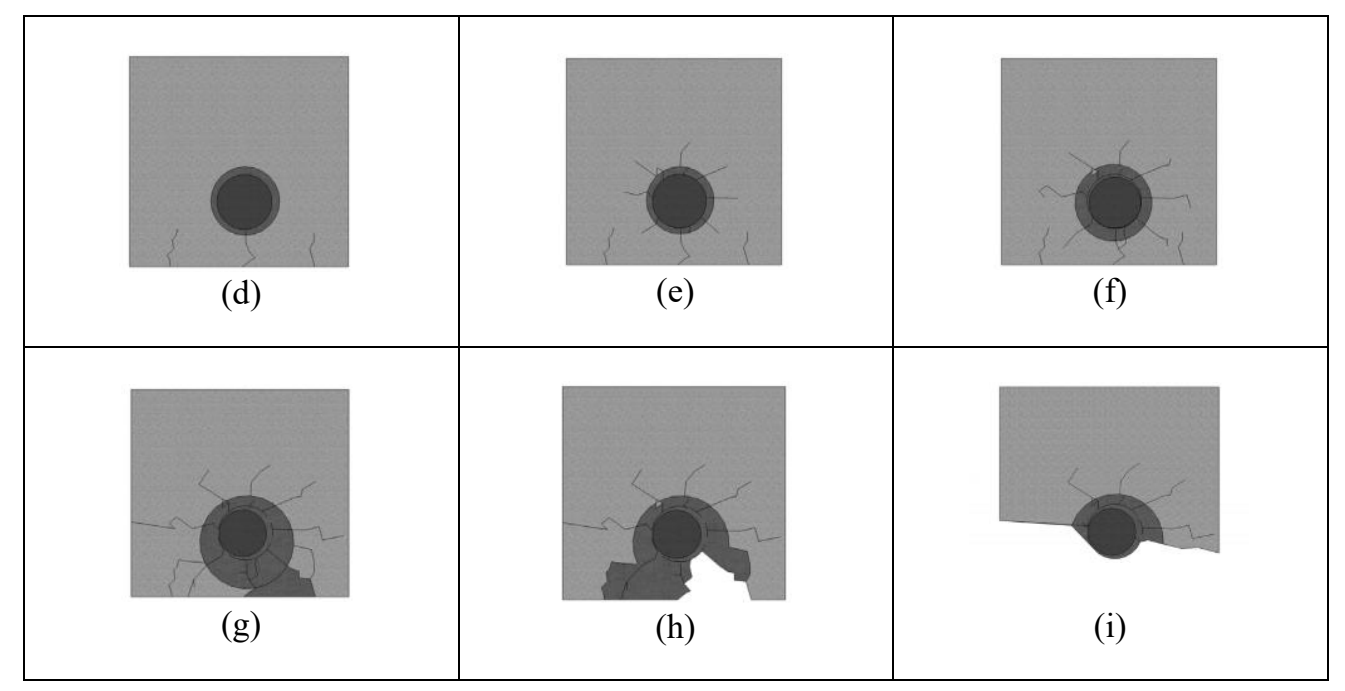

Figure 1. Chloride induced corrosion and cracking (Arndt/Jalinoos 2009, p.3). a) Fresh cast and hardening concrete. b) Early local structural, thermal and fatigue cracking. c) Migration of chloride; no corrosion. d) Initial corrosion of steel and formation of corrosion products; no stresses ( $\left.t_{\text {init }}\right)$. e) Radial hoop stresses with formation of cracks and starting chemical alteration of concrete. f) Increased cracking around steel and starting concrete spalling. g) Enhanced oxygen, moisture and chloride inflow; development of radial macrocracks, spalling and delaminations. h) Cumulating damage. i) End of life performance.

Ideally these damage phases can be monitored by periodic non-destructive testing (NDT) as proposed by (Jalinoos et al. 2009, Arndt/Jalinoos 2009) using varying NDT technologies for the different phases, i.e. chain drag, infrared thermography or impact echo for phases $\mathrm{g}$ and $\mathrm{h}$ (delaminations and spalling). Here various non-destructive and semi-destructive testing (SDT) methods are available with varying information value (Alampalli/Jalinoos 2009, Oh et al. 2013, Gucunski et al. 2013).

Both authors of this contribution have been involved in the evaluation of existing corrosion detection techniques like half-cell potential [7, 11 as part of their professional careers in the US Federal Highway Administration (FHWA, see quotations above) and the German Federal Highway Research Institute (BASt, Gatz/Quaas 2000), leading them to the development and invention of the Active Electrochemical Corrosion, Ion mobility and Passivation (AECIP) testing method for steel reinforced concrete at FH Erfurt (international patent WO/2018/091534, Arndt/Gatz 2017).

The goal for the development of the new method by FHE is to have a testing method that not only enables a reliable location of active or passive corrosion, but also a characterization of current and future passivation behavior of the reinforcement in interaction with concrete mixtures, processing, post-treatment and repairs of buildings and components made of reinforced concrete i.e. for quality assurance, the optimization of concrete, cement and mortar mixtures and formulations as well as other potential applications such as building monitoring and active corrosion protection.

\section{THE AECIP TESTING METHOD}

\section{A Short Description of The New Method from FH Erfurt}

The new testing method AECIP is an active testing method developed for active corrosion localization and passivation evaluation of steel reinforcement in concrete as well as the prediction of corrosion and passivation tendencies. To achieve these goals, it uses at least one active electrical test signal - usually at $10 \mathrm{~Hz}$ with $+400 \mathrm{mV}$ - which normally feeds into the reinforcing steel as a square wave signal. For this purpose, a direct contact with the reinforcement has to be made, as for half-cell potential, which 
is why AECIP can be characterized as a semi-destructive and not a pure nondestructive testing method. A second, additional, active signal fed to the measuring head on the concrete surface increases the measuring reliability, the measuring possibilities and the reliability of associated interpretations. This second test signal fed into the measuring electrode, can be set via freely selectable series resistors. The optimum voltage of the secondary signal, which can be regarded as an active cathodic protection current, is usually set at $-400 \mathrm{mV}$ as the basic voltage, thus balancing the first test signal. As a result, reliable measurement information on building-related parameters and in particular the passable boundary surface between the steel reinforcement and the concrete cement-stone are possible in the laboratory, but also potentially within the framework of structural inspections on site. Another special feature of AECIP is the determination of the actual and measurementrequired ion movement in this interface, without which no meaningful and wellfounded corrosion and passivation assessment can be made, since the corrosion behavior of the reinforcement is defined by moisture in the interface between steel and concrete. Only the assessment of this interface moisture makes it possible to make a sound statement. The schematic drawing of the AECIP principle as printed in the in the international patent (Arndt/Gatz 2017, Fig. 1) can be seen in figure 2.

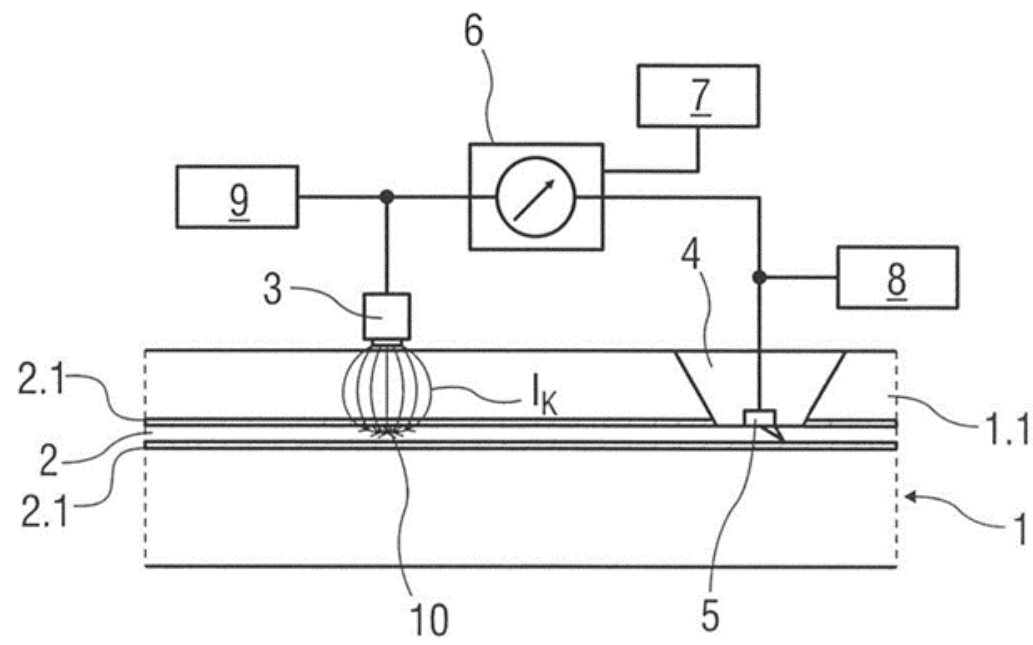

Figure 2. Schematic drawing of the AECIP principle (Arndt/Gatz 2017, Fig. 1). 1 Concrete member; 1.1 Outer concrete layer; 2 Reinforcing steel; 2.1 Passivation layer; 3 Measuring electrode; 4 Contact opening; 5 Rebar connection; 6 Measurement device; 7 Data processing unit; 8 Test signal; 9 Cathodic protective current source; 10 Corrosion location.

\section{Description of the Measuring Curves}

The incoming signals in the measuring electrode are prepared by means of an electrical circuit and sent to a computer unit. The incoming digital converter signals can be displayed graphically over time or stored for further processing. By means of figure 3 (Arndt/Gatz 2017, Fig. 5) it shall be explained how the resulting measurement curves can be interpreted. 


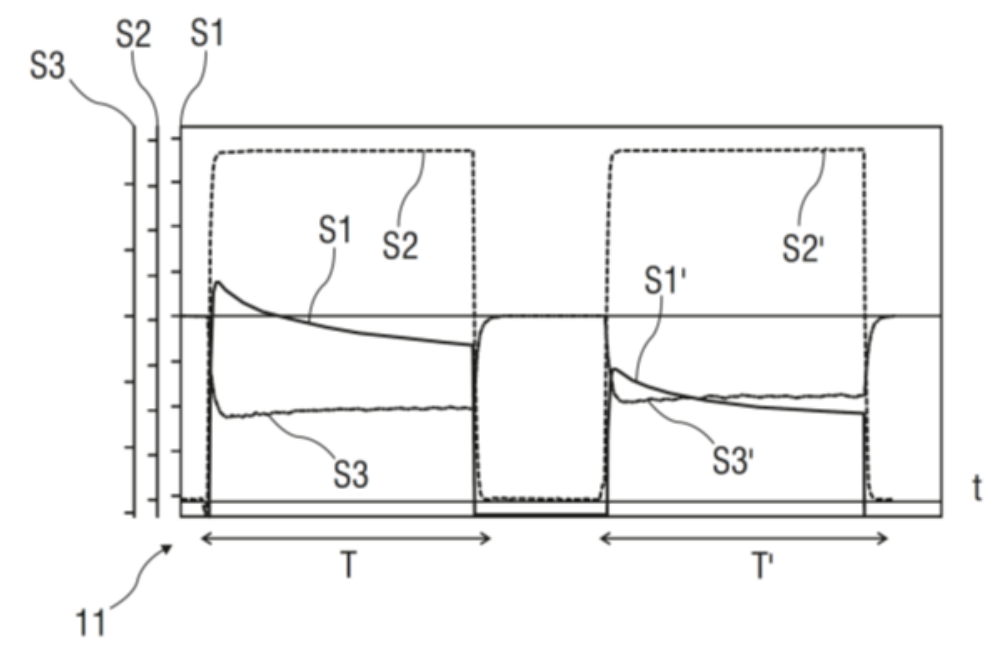

Figure 3. Resulting measurements curves (11) of the AECIP testing method (Arndt/Gatz 2017, Fig. 5) over time T and T' for a corroding rebar to the left and a passivated one to the right with corrosion curve S1, S1', moisture curve S2. S2' and cathodic curve S3, S3'.

Corrosion Curve / S1, S1'. The so-called "corrosion curve" is the one that allows conclusions to be drawn about the passivation or corrosion state of the reinforcement and the passivation layer according to measured value and the inclination of the curve, in context with the other curves. In the case of the presented examples curve S1 indicates active corrosion and $\mathrm{S} 1$ ' intact passivation.

Ion Mobility / S2, S2'. The so-called "ion mobility" or "moisture" curve indicates the ion mobility in the passivation layer. It is related to the prevailing moisture and indicates whether a measurement can be carried out successfully. In the case of the presented examples both curves indicate ion activity that allows a qualified measurement.

Cathodic Protection Current / S3, S3'. The "cathodic curve" indicates the cathodic current and is directly related to the corrosion curve. Through this curve, conclusions can be drawn on the required external electron supply to prevent the anodic and cathodic sub-processes and promote passivation.

\section{SUMMARY AND OUTLOOK}

Corrosion causes annual damage worth billions of dollars in many industries, as well as the construction sector, in the US alone (NACE 2001), and it can be assumed in Asia, Europe and worldwide as well. In particular, there is no reliable testing method for characterizing the passivation and the durability of steel in reinforced and prestressed concrete. This motivated the development and invention of the new semidestructive testing method AECIP by FH Erfurt (Arndt/Gatz 2017), a method for assessing the corrosion as well as passivation behavior of steel reinforced concrete.

Analyzing and interpreting all measurement curves opens many possibilities for application. It is the conviction of the authors that AECIP thus not only provides the opportunity to detect corrosion and characterize passivation, it also allows evaluating passivation and corrosion tendencies in the future. Perceptively, it could therefore be used not only for building diagnostics but in particular, for concrete mixtures and reinforcement optimization and quality assurance, i.e. by monitoring passivation layers and the associated concrete formulations in regard to their durability.

\section{ACKMOWLEDGMENTS}

The authors wish to thank FH Erfurt and PATON for financial, technical and organizational support, i.e. in patenting and in the frame of the research funding initiative FFI of FH Erfurt. 


\section{REFERENCES}

Broomfield, J. P. (2007). "Corrosion of Steel in Concrete: Understanding, Investigation and Repair”, E\&FN Spon, London, Great Britain, 277p.

National Association of Corrosion Engineers (NACE). (2001). "Corrosion Costs and Preventive Strategies in the United States", United States.

Melchers, R. E., Li, C. Q. (2006). "Phenomenological Modeling of Reinforcement Corrosion in Marine Environments", ACI Materials Journal, Vol.103, No.1, pp.2532.

Weyers, R. E., Fitch, M. G., Larsen, E. P., Al-Qadi, I. L., Chemberlin, W. P., and Hoffman, P. C. (1994). "Concrete Bridge Protection and Rehabilitation: Chemical and Physical Techniques", SHRP-S-668, Strategic Highway Research Program, National Research Council, Washington Dc, United States, 357p.

Chen, D., and Mahadevan S. (2008). "Chloride-induced reinforcement corrosion and concrete cracking simulation", Cement \& Concrete Composites, Vol. 30, pp. 227238.

Arndt, R., and Jalinoos, F. (2009). "NDE for corrosion detection in reinforced concrete structures - a benchmark approach", Proc. of NDTCE, Nantes, France.

Jalinoos, F. Arndt, R., Huston, D, and Cui, J. (2009). "Structural Health Monitoring by Periodic NDT: NDT for Bridge Maintenance", Materials Evaluation, Volume 67(11), S. 1300-1307.

Alampalli, S., and Jalinoos, F. (2009). "Use of NDT Technologies in US Bridge Inspection Practice", Materials Evaluation, Volume 67(11), S. 1236-1246.

Oh, T., Kee, S.-H Popovics, J., Arndt, R., and Zhu, J. (2013). “Comparison of NDT Methods for Assessment of Concrete Bridge Decks", ASCE Journal of Engineering Mechanics Special Issue, "Experimental Methods in Damage Detection and Wind Engineering", 305-314.

Gucunski, N. et al. (2013) "Nondestructive Testing to Identify Concrete Bridge Deck Deterioration", Report (SHRP 2) S2-R06A-RR-1, Washington, D.C.: Transportation Research Board.

Gatz, H.-P. and Quaas, B. (2000). „B 29: Complementary study to determine the carbonation depth and chloride content of concrete“, BASt, Bergisch-Gladbach, 36 p., in German.

Arndt, R., and Gatz, H.-P. (2017). "Method and arrangement for assessing corrosion and passivation of reinforcement while taking into account the moisture in reinforced concrete". International Patent: WO/2018/091534, published in German (German Patent: DE102016222538B3), owner: FH Erfurt. 